\title{
Downstream Effects: Impact of Antibiotic Pollution on Aquatic Host-Parasite Interactions
}

Hannah G. Melchiorre ${ }^{1}$, Stephanie O. Gutierrez ${ }^{1}$, Dennis J. Minchella ${ }^{1}$, and J. Trevor Vannatta ${ }^{1}$

${ }^{1}$ Department of Biological Sciences, Purdue University, West Lafayette, Indiana, USA 47907

\section{$\underline{\text { Abstract }}$}

The global increase in antibiotic use has led to contamination of freshwater environments occupied by parasites and their hosts. Despite the identified impacts of antibiotics on humans and wildlife, the effect of antibiotics on host-parasite life cycles is relatively unexplored. We utilize the trematode parasite Schistosoma mansoni, and its snail intermediate host Biomphalaria glabrata to explore the influence of an ecologically relevant antibiotic concentrations on the life history characteristics of both parasite and host. Our results demonstrate that antibiotics not only accelerate parasite development and have a positive effect on parasite reproduction, but also increase the likelihood of host egg laying, and delay parasite-induced host castration. Using a mathematical model, we suggest that these life history alterations associated with antibiotics are likely to increase parasite transmission and disease burden. 


\section{Downstream Effects: Impact of Antibiotic Pollution on Aquatic Host-Parasite Interactions}

\section{Introduction}

Antibiotic usage is increasing worldwide in association with growing demand in livestock production, industry, and human healthcare (Daghrir et al., 2013). As a result, antibiotic contamination from wastewater treatment plants and sewers often end up in freshwaters (Kraemer et al., 2019). Presence of antibiotics in aquatic environments affects the life forms within them, extending beyond microscopic organisms to other non-target species (Danner et al., 2019, Sundberg et al., 2018). Although antibiotic concentrations in freshwater are not typically lethal to non-target organisms, the sublethal impact of runoff on biotic interactions is largely unknown (Cairns et al., 2018, Kim et al., 2014).

The magnitude and severity of antibiotic contamination can have diverse effects depending on the nature of the biotic system (Sundberg et al., 2018). Antibiotics can act as environmental stressors to alter bacterial communities through direct or indirect mechanisms (Grenni et al., 2018). They are designed to decrease pathogenic bacteria within the organism; however, they also impact overall bacterial community diversity within the microbiome and alter community function (Yoon et al., 2018, Morley, 2010, Akbar et al., 2020). Research has shown that the microbiome plays a third-party role in host-parasite interactions (Knutie et al., 2017), however, there is little evidence supporting the effects of sublethal antibiotic exposure on hostparasite interactions (Morley, 2009). Antibiotics likely have widespread impacts on many hostparasite systems either directly (by influencing the organisms involved) or indirectly (by influencing predators/prey/parasites of the organisms involved) (Pravdová et al., 2020). Tetracycline is a common broad-spectrum antibiotic that contaminates freshwater environments due to its water solubility and widespread use in agriculture (Lin et al., 2013). Connections have 
also been drawn between high rates of tetracycline consumption with prevalence of disease in high-risk areas (Faleye et al., 2018).

Schistosoma mansoni is a parasitic blood-fluke that causes the human disease schistosomiasis in tropical regions and accounts for as many as 200,000 annual deaths (Adenowo et al., 2015, Verjee, 2019). Eggs of $S$. mansoni from infected humans hatch into miracidia, a larval stage of the parasite, when they contact freshwater. These miracidia can penetrate the snail intermediate host, Biomphalaria glabrata. Maturation of the parasite occurs within the snail gonads leading to castration of the host. The snails release free-swimming larval stages called cercariae which directly infect humans as the definitive host (CDC, 2018).

Given the human toll of schistosomiasis and the use of antibiotics in medicine and agriculture in tropical regions (Faleye et al., 2018), we designed an experiment to analyze the effects of antibiotic contamination on S. mansoni development rate and reproductive output, as well as host fecundity. The antibiotic chosen for this experiment was tetracycline due to its water solubility, easy accessibility, and widespread use in agriculture and human medicine (Daghrir et al., 2013). Based on previous evidence of increased growth and reproduction in some species through antibiotic exposure (Flaherty et al., 2005, Gaskins et al., 2002), we hypothesized that tetracycline would accelerate parasite development time, increase reproductive output in parasites, and enhance host reproduction. We further use our results to parameterize an epidemiological model and demonstrate potential long-term consequences of freshwater antibiotic contamination on human disease burden.

\section{Methods}

One hundred sixty lab-reared B. glabrata snails were used in a full factorial experiment combining parasitic infection and antibiotic exposure. Forty snails per treatment group were size- 
matched ranging from $8-13 \mathrm{~mm}$ in shell diameter and placed in $120 \mathrm{ml}$ individual jars. Well water and antibiotic treatments were further categorized into unexposed or exposed to $S$. mansoni for a total of four treatments (antibiotic + parasite, parasite only, antibiotic only, control; see Table 1). Prior to parasite exposure, snails underwent a 4-day acclimation period in well water or well water with the set concentration of antibiotic. Ecologically relevant concentrations of tetracycline vary from region to region, but $50 \mu \mathrm{g} / \mathrm{L}$ is a common concentration in areas near waste treatment plants and was used for this experiment (Daghrir et al., 2013). A 50 $\mu \mathrm{g} / \mathrm{L}$ solution of antibiotic was replaced every 7 days to maintain efficacy and minimize the impact of antibiotic degradation (Schmidt et al., 2007). Antibiotic solutions were prepared by dissolving $1 \mathrm{mg}$ of tetracycline (Research Products International, Tetracycline HCl, Lot \#36063-101361) in 20 L of well-water a few hours prior to use.

Each snail in the parasite only treatment and antibiotic + parasite treatment was exposed to 8 miracidia of $S$. mansoni for 24 hours. Unexposed snails were sham exposed for the same period of time. Miracidia were harvested from livers of infected mice (in accordance with Purdue Animal Care and Use Committee protocol \#1111000225) by blending in saline and filtering according to standard protocols (Tucker et al., 2013). To quantify host reproductive output, egg masses were counted and removed from all snail housing jars weekly for 9 weeks. To determine the impact of antibiotics on the rate of development of the parasite and infection prevalence in snails, cercarial output was assessed in B. glabrata beginning week 4 post exposure weekly until the end of the experiment at week 9. This window coincides with the patent period of parasite development which normally involves 4 weeks of parasite development where no parasite release occurs, followed by release of cercariae (termed shedding) beginning week 4 or later. 
In order to measure parasite reproduction, snails were placed in well plates with $10 \mathrm{~mL}$ of well water and positioned under fluorescent light to allow parasite emergence. After 60 minutes, snails were returned to their respective jars and the presence or absence of cercariae was recorded. If parasites were detected, a $1 \mathrm{~mL}$ aliquot of well water was taken and all cercariae within the aliquot counted (Gleichsner et al., 2016). Finally, the survival of snails was checked weekly.

\section{Statistical analysis}

Data on parasite and host reproduction had considerable zero-inflation. As such, we constructed mixed effects hurdle models to account for data overdispersion using the glmmTMB package in R (Brooks et al. 2017). Hurdle models first model the probability of obtaining a zerovalue, similar to logistic regression. Then, if the value is non-zero, hurdle models use a specific error distribution to further predict host/parasite reproduction. As such, all hurdle model outputs contain coefficients for a zero-inflated model, predicting the probability of a zero, and a conditional model, predicting non-zero measurements based on a specific error distribution. Models were fit with treatment, week, and treatment * week interactions terms as fixed effects except where inclusion of the interaction term was uninformative. Additionally, we generated hurdle models using both a Poisson and negative binomial error distribution for non-zero values and used AIC to determine which model best fit the data. In our models, individual host ID was treated as a random factor. To compare overall prevalence and the proportion of hosts releasing parasites in week 4, we used a two-sample test of equal proportions. Survival analysis was run on all individuals within a treatment group, irrespective of infection status. This was necessary as infection cannot be definitively confirmed until week 6 , meaning infected individuals who died prior to shedding would be unknown. A Cox proportional hazard regression model was run in $\mathrm{R}$ 
3.6.3 using the survival and survminer packages. Analysis was conducted over the course of the

9-week experiment and used to parameterize daily mortality rates within our mathematical model.

Lastly, we adapted an existing schistosomiasis model (Hoover et al., 2020) and altered parameters in proportion to our data on control versus antibiotic conditions. This analysis was done to further examine how antibiotic contamination may impact human schistosomiasis. Extended discussion of the model, equations, and parameter values can be found in the supplement (Table S1).

\section{$\underline{\text { Results }}$}

\section{Parasite Reproduction}

Antibiotics accelerated parasite development. A significantly higher proportion of antibiotic + parasite snails were releasing parasites in week $4(56 \%)$ compared to parasite only snails $\left(5 \% ; \chi^{2}=10.317, \mathrm{p}=0.001\right.$, Figure 1$)$. Although a significantly greater proportion of shedding occurred in the antibiotic + parasite treatment, the number of cercariae released was low. As such, the impact of early maturation may be limited. Infection prevalence for the antibiotic + parasite and parasite only treatments were not significantly different at $77 \%$ and $59 \%$, respectively $\left(\chi^{2}=1.696, p=0.193\right)$. Additionally, antibiotics had a positive effect on parasite reproduction over time such that both parasite treatments have similar parasite output in early weeks, with the antibiotic + parasite treatment releasing more cercariae as the infection matures (Figure 2 and Table 2).

\section{Host Reproduction}


Snails in the antibiotic treatment were more likely to lay eggs relative to snails in the control treatment (Table 3, p $=0.005$, Figure 3a). The antibiotic + parasite treatment had a higher probability of laying eggs than the parasite only treatment throughout the entire experiment (Table $4, p=0.006$ ). Additionally, comparison of the parasite treatment and antibiotic + parasite treatment suggests an initially similar reproductive output (Figure S1), yet as the infection matured, snails within the antibiotic + parasite treatment have a higher probability of laying eggs showing delayed castration compared to the parasite only treatment (Figure 3b). The observed decrease in eggs laid over time in infected snails is due to parasitic castration.

The antibiotic only treatment showed the highest survival, followed sequentially by the control treatment, then parasite only treatment, and antibiotic + parasite treatment (Figure 4). The pairwise, Cox proportional hazard comparisons including coefficient, $\mathrm{z}$ ratio, and $\mathrm{p}$ value are as follows: Control vs antibiotic: $0.419, \mathrm{z}=0.967, \mathrm{p}=0.333$; Control vs parasite: $-0.121, \mathrm{z}=$ $0.314, \mathrm{p}=0.753 ;$ Antibiotic vs antibiotic + parasite: $-0.872, \mathrm{z}=-2.187, \mathrm{p}=0.029 ;$ Antibiotic + parasite vs parasite: $0.332, \mathrm{z}=0.961, \mathrm{p}=0.337$. Observed differences were only significant when comparing the antibiotic + parasite and antibiotic only treatment $(z=-2.187, p=0.029)$.

Based on our adaptation of a published S. mansoni model, we expect areas with antibiotic contamination to have increased snail exposure to parasites and more rapid snail population growth, leading to higher infection prevalence in snails and greater worm burdens in humans (Figure 5). Additionally, snail exposure and human worm burdens increase more rapidly in the antibiotic scenario than would otherwise occur.

\section{$\underline{\text { Discussion }}$}


We investigated the impact of an ecologically relevant concentration of tetracycline on the life history parameters of the trematode parasite $S$. mansoni and its snail intermediate host, $B$. glabrata. We assessed host reproduction and survival as well as parasite reproduction and development time in the presence and absence of the antibiotic, tetracycline. Our results suggest that antibiotics are likely to impact snail and parasite reproduction with potentially significant ecological ramifications. We show that tetracycline facilitated earlier cercarial release by infected hosts and increased cercarial output as the infection matured (Figure 2). Additionally, the presence of antibiotics increased egg laying in uninfected snails when compared to uninfected, well water controls (Table 3). Lastly, parasitic castration is delayed in the antibiotic + parasite snails, and they have a significantly higher egg output throughout the experiment compared to the parasite only treatment (Table 4). To the best of our knowledge, this is the first study to document the impact of antibiotic contamination on the host and parasite life cycle parameters of this freshwater snail and its medically relevant parasite.

These modifications in host-parasite interactions by antibiotic contamination are likely associated with changing microbiome dynamics (Hernández-Gómez et al., 2020, Knutie et al., 2017). Antibiotics specifically have been found to disturb microbiomes by decreasing useful or increasing harmful bacteria (Akbar et al., 2020). The alterations observed in parasite development time, parasite reproduction, and host reproduction from addition of tetracycline are congruent with research findings of microbiome-related impaired immune function following parasitic infection (Portet et al., 2018). Portet et al. (2018) suggested that following infection of S. mansoni, the bacterial microbiome of B. glabrata changed its composition, which could account for the altered immune function. Decreased immune function weakens defense mechanisms within hosts (Akbar et al., 2020), which can increase susceptibility to parasites and 
corresponds with our findings of an accelerated parasite development time in the antibiotic + parasite treatment (Pravdová et al., 2020). A potential alternative explanation is that the parasites were more aggressively exploiting their host, indicating increased parasite pathogenicity (Anzia et al., 2018, Schlüter-Vorberg et al., 2019).

Another finding consistent with an altered microbiome was the significant increase of parasite reproduction in the antibiotic + parasite treatment compared to the parasite only treatment. A study conducted by Schlüter-Vorberg et al. (2019) found similar results when studying the effects of pharmaceuticals on pathogen virulence in a host-parasite system. They demonstrated that chemically induced suppression of immune systems in Daphnia weakens disease resistance by enhancing the virulence of the parasite and increases the proportion of infected hosts (Schlüter-Vorberg et al., 2019). However, they additionally observe an increased speed of host sterilization, which contrasts our findings of a delayed castration period in hosts. Our initial survival data suggested that the observed increase in reproductive output may also be associated with increased mortality within infected snails in the antibiotic treatment which could result in a net decrease in parasite fitness. However, our model proposes that the increased mortality in infected snails is not sufficient to balance the other life history alterations associated with antibiotic exposure. Considering all factors, parasite transmission and thus disease burden in humans are likely to increase in regions with sufficient antibiotic concentrations.

Finally, hosts exposed to antibiotics were more likely to lay eggs. Increased reproduction due to antibiotic exposure has also been shown in other studies of invertebrates (Flaherty et al., 2005). A similar study investigating the effect of pharmaceuticals on Daphnia reproduction found that chronic exposure to certain types of antibiotics induced significantly greater development and reproduction measurements (Flaherty et al., 2005). These influences on typical 
development patterns varied depending on both the duration of exposure, and number of pharmaceuticals to which they were exposed. The strongest and most complex effects between fecundity and antibiotics were observed with long term (30-day) exposure and a combination of multiple pharmaceuticals mixtures, respectively. This potential alteration to snail population dynamics could have cascading impacts within food webs as snails are important herbivores and prey within many systems (Johnson, 2009). The capacity to change food web dynamics could also manifest as an increased antibiotic sensitivity in primary producers such as algae, affirming the potential risks of contamination in non-target species that could influence snail-host populations (Isidori et al., 2005).

\section{$\underline{\text { Conclusion }}$}

We are only beginning to understand the impacts of antibiotics on hosts, parasites, and their interactions. Here, we show that antibiotics influence parasite dynamics by facilitating earlier cercarial release and increasing cercarial output as the infection matures. Infected hosts affected by antibiotic contamination demonstrated increased egg laying and egg output throughout the experiment when compared to the parasite only treatment. In addition, parasite castration was delayed in hosts exposed to antibiotics. Our study suggests that the continued widespread use of antibiotics with improper disposal results in residual consequences to freshwater ecosystems and may increase the burden of schistosomiasis in endemic regions. The largely unknown ecological and anthropogenic impacts of antibiotic contaminants including - but not limited to - trophic effects, disease risk, and ecosystem interactions therefore merits further research. As antibiotic usage increases, its role as a link between human health and host-parasite interactions emphasizes the need to further explore the consequences of human activity on all facets of global change. 


\section{Conflict of Interest}

The authors declare that they have no conflict of interest.

\section{Statement of Human and Animal Rights:}

All applicable institutional and/or national guidelines for the care and use of animals were

followed in accordance with Purdue Animal Care and Use Committee protocol \#1111000225.

\section{Informed Consent:}

This study did not involve human subjects. 


\section{$\underline{\text { References }}$}

Adenowo AF, Oyinloye BE, Ogunyinka BI, Kappo AP (2015) Impact of human schistosomiasis in sub-Saharan Africa. The Brazilian Journal of Infectious Disease 11(2): 196-205; DOI: https://doi.org/10.1016/j.bjid.2014.11.004 [Online January 27, 2015]

Akbar A, Gu L, Sun Y, Zhou Q, Zhang L, Lyu K, Huang Y, Yang Z (2020) Changes in the life history traits of Daphnia magna are associated with the gut microbiota composition shaped by diet and antibiotics. Science of The Total Environment 705(135827); DOI: https://doi.org/10.1016/j.scitotenv.2019.135827 [Online November 30, 2019]

Anderson RM, May RM (1991) Infectious Diseases of Humans: Dynamics and Control, New York: Oxford University Press

Anzia EL, Rabajante JF (2018) Antibiotic-driven escape of host in a parasite-induced Red Queen dynamics. Royal Society 5(9); DOI :https://doi.org/10.1098/rsos.180693 [Online September 12, 2018]

Cairns J, Ruokolainen L, Hultman J, Tamminen M, Virta M, Hiltunen T (2018) Ecology determines how low antibiotic concentration impacts community composition and horizontal transfer of resistance genes. Communications Biology 35; DOI: https://doi.org/10.1038/s42003-018-0041-7 
Brooks ME, Kristensen K, van Benthem KJ, Magnusson A, Berg CW, Nielsen A, Skaug HJ, Maechler M, Bolker BM (2017) glmmTMB balances speed and flexibility among packages for zero-inflated generalized linear mixed modeling. R J 9:378-400

CDC (2018) Schistosomiasis - Biology.

Available:https://www.cdc.gov/parasites/schistosomiasis/biology.html [accessed September 1, 2020]

Daghrir R, Droghui P (2013) Tetracycline antibiotics in the environment: A review. Environmental Chemistry Letters 11:209-227; DOI: https://doi.org/10.1007/s10311-0130404-8

Danner M, Robertson A, Behrends A, Reiss J (2019) Antibiotic pollution in surface fresh waters: Occurrence and effects. Science of the Total Environment 664:793-804; DOI: https://doi.org/10.1016/j.scitotenv.2019.01.406 [Online February 5, 2019]

Faleye AC, Adegoke AA, Ramluckan K, Bux Faizal, Strenstrom TA (2018) Antibiotic residue in the aquatic environment: Status in Africa. Open Chemistry 16(1):890-903; DOI: https://doi.org/10.1515/chem-2018-0099 [Online September 3, 2018]

Flaherty CH, Dodson SI (2005) Effects of pharmaceuticals on Daphnia survival, growth, and reproduction. Chemosphere 61(2):200-207; DOI: https://doi.org/10.1016/j.chemosphere.2005.02.016 [Online April 9, 2005] 
Gaskins HR, Collier CT, Anderson DB (2002) Antibiotics as growth promotants:

Model of action. Animal Biotechnology 13(1):29-42;

DOI: 10.1081/ABIO-120005768 [Online December 11, 2006]

Gleichsner AM, Cleveland JA, Minchella DJ (2016). One stimulus - Two responses: Host and parasite life-history variation in response to environmental stress. Evolution 70(11):26402646; DOI: https://doi.org/10.1111/evo.13061

Goddard MJ, Jordan P (1980) On the longevity of Schistosoma mansoni in man on St. Lucia, West Indies. Transactions of The Royal Soiety of Tropical Medicine and Hygiene 74:185-191; DOI: https://doi.org/10.1016/0035-9203(80)90240-0

Grenni P, Ancona V, Caracciolo AB (2018) Ecological effects of anitbiotics on natural ecosystems: A review. Microchemical Journal 136:25-39; DOI: https://doi.org/10.1016/j.microc.2017.02.006 [Online February 10, 2017]

Hernández-Gómez O, Wuerthner V, Hua J (2020) Amphibian host and skin microbiota response to a common agricultural antimicrobial and internal parasite. Microbial Ecology 79:175191; DOI: https://doi.org/10.1007/s00248-019-01351-5

Hoover CM, Rumschlag SL, Strgar L, Arakala A, Gambhir M, de Leo GA, Sokolow SH, Rohr JR, Remais JV (2020) Effects of agrochemical pollution on schistosomiasis transmission: 
A systematic review and modelling analysis. Lancet Planet Heal 4:280-291; DOI:

https://doi.org/10.1016/S2542-5196(20)30105-4

Isidori M, Lavorgna M, Nardelli A, Pascarella L, Parrella A (2005) Toxic and genotoxic evaluation of six antibiotics on non-target organisms. Science of the Total Environment 316(1-3):87-98; DOI: https://doi.org/10.1016/j.scitotenv.2004.11.017 [Online January 29, 2005]

Johnson PD (2009) Sustaining America's aquatic biodiversity: Freshwater snail biodiversity and conservation. Virginia Cooperative Extension Publication 420-530.

Kim HY, Yu S, Jong T, Kim SD (2014) Relationship between trans-generational effects of tetracycline on Daphnia magna at the physiological and whole organism level. Environmental Pollution 191:111-118; DOI: https://doi.org/10.1016/j.envpol.2014.022

Knutie SA, Gabor CR, Kohl KD, Rohr JR (2017) Do host-associated gut microbiota mediate the effect of a herbicide on disease risk in frogs? Journal of Animal Ecology 87(2):489-499; DOI: https://doi.org/10.1111/1365-2656.12769

Kraemer SA, Ramachandran A, Perron GG (2019) Antibiotic pollution in the environment: From microbial ecology to public policy. Microorganisms 7(6):180; DOI: https://doi.org/10.3390/microorganisms7060180 
Lin Y, Xu S, Jia Li (2013) Fast and highly efficient tetracyclines removal from environmental waters by graphene oxide functionalized magnetic particles. Chemical Engineering Journal 225:679-685; DOI: https://doi.org/10.1016/j.cej.2013.03.104 [Online April 6, 2013]

McLellan SL, Newton RJ, Fisher J (2015) The microbiome of urban waters. International Microbiology 18:141-149; DOI: 10.2436/20.1501.01.244

Minchella DJ, Loverde PT (1981) A cost of increased early reproductive effort in the snail Biomphalaria glabrata. The American Naturalist 118(6):876-881; DOI: https://doi.org/10.1086/283879

Morley N (2010) Interactive effects of infectious diseases and pollution in aquatic molluscs. Aquatic Toxicology 96(1):27-36; DOI: https://doi.org/10.1016/j.aquatox.2009.09.017 [Online October 3, 2009]

Morley N (2009) Environmental risk and toxicology of human and veterinary waste pharmaceutical exposure to wild aquatic host-parasite relationships. Environmental Toxicology and Pharmacology 27(2):161-175; DOI:

https://doi.org/10.1016/j.etap.2008.11.004 [Online November 21, 2008] 
Portet A, Toulza E, Lokmer A, Huot C, Duval D, Galinier R, Gourbal B (2018) Infection of the Biomphalaria Glabrata vector snail by Schistosoma mansoni parasites drives snail microbiota dysbiosis. BioRxiv; DOI: https://doi.org/10.1101/386623

Pravodá M, Kolářova J, Grabicová K, Mikl L, Bláha M, Randák T, Kvsch Y, Jurjda P, Ondračková M (2020) Associations between pharmaceutical contaminants, parasite load and health status in brown trout exposed to sewage effluent in a small stream. Ecohydrology \& Hydrobiology; DOI: https://doi.org/10.1016/j.ecohyd.2020.09.001 [Online September 15, 2020]

Schlüter-Vorberg L, Coors A (2019) Impact of an immunosuppressive human pharmaceutical on the interaction of a bacterial parasite and its invertebrate host. Aquatic Toxicology 206:91-101; DOI: https://doi.org/10.1016/j.aquatox.2018.11.007 [Online November 14, 2018]

Schmidt LJ, Gaikowski MP, Gingerich WH, Dawson VK, Schreier TM (2007) An environmental assessment of the proposed use of oxytetracycline-medicated feed in freshwater aquaculture. U. S. Geological Survey, Biological Resources Division. Available: https://animaldrugsatfda.fda.gov/adafda/app/search/public/document/downloadEA/156 [accessed September 4, 2020]

Soetaert K, Petzoldt T, Setzer RW (2010) Solving differential equations in R: Package deSolve. Journal of Statistical Software 33(9):1-25 
Sokolow SH, Huttinger E, Jouanard N, Hsieh MH, Lafferty KD, Kuris AM, Riveau G, Senghor S, Cheikh T, N'Diaye A, Faye DS, De Leo GA (2015) Reduced transmission of human schistosomiasis after restoration of a native river prawn that preys on the snail intermediate host. Proceedings of the National Academy of Sciences of the United States of America 112:9650-9655; DOI: https://doi.org/10.1073/pnas.1712011114

Sundberg LR, Karvonen A (2018) Minor environmental concentrations of antibiotics can modify bacterial virulence in co-infection with a non-target parasite. Royal Society 14(12); DOI: https://doi.org/10.1098/rsbl.2018.0663

Tchounwou PB, Englande AJ, Malek EA, Greer GJ, Anderson (1991) The effects of bayluscide and malathion on the mortality and infectivity of Schistosoma mansoni miracidia. $J$ Environmental Science and Health Part B 26:69-82; DOI: https://doi.org/10.1080/03601239109372724

Tchounwou PB, Englande AJ, Malek EA, Greer GJ, Anderson (1992). The effects of bayluscide and malathion on the mortality and infectivity of Schistosoma mansoni cercariae. Environmental Toxicology and Water Quality 7(2):107-117; DOI: https://doi.org/10.1002/tox.2530070202

Tucker MS, Karunaratne LB, Lewis FA, Freitas TC, Yiang Y (2013) Schistosomiasis. Current Protocols in Immunology 103(1); DOI: https://doi.org/10.1002/0471142735.im1901s103 
Verjee MA (2019) Schistosomiasis: Still a cause of significant morbidity and mortality.

Research and Reports in Tropical Medicine 10:153-163; DOI: 10.2147/RRTM.S204345

Willing BP, Russell SL, Finlay BB (2011) Shifting the balance: Antibiotic effects on hostmicrobiota mutualism. Nature Reviews Microbiology 9:233-243; DOI:

https://doi.org/10.1038/nrmicro2536

Woolhouse MEJ, Chandiwana SK (1990) Population biology of the freshwater snail biomphalaria pfeifferi in the Zimbabwe highveld. Journal of Applied Ecology 27:41-59; DOI: $10.2307 / 2404477$

Yoon MY, Yoon SS (2018) Disruption of the gut ecosystem by antibiotics. Yonsei Medical Journal 59(1):4-12; DOI: 10.3349/ymj.2018.59.1.4 [Online November 29, 2017]

Zhang S, Chen D (2019) Facing a new challenge: the adverse effects of antibiotics on gut microbiota and host immunity. Chinese Medical Journal 132(10):1135-1138; DOI: $\underline{10.1097 / \mathrm{CM} 9.0000000000000245}$ 
Table 1. Treatment groups designated by presence or absence of antibiotic and/or parasite, $\mathrm{N}=$ sample size after acclimation and with active infections for parasite $(+)$ treatments.

\begin{tabular}{|l|l|l|}
\hline & Antibiotic $(+)$ & Antibiotic (-) \\
\hline Parasite $(+)$ & Antibiotic + parasite $(\mathrm{N}=27)$ & Parasite only $(\mathrm{N}=19)$ \\
\hline Parasite (-) & Antibiotic only $(\mathrm{N}=33)$ & Control(N=34) \\
\hline
\end{tabular}

Table 2. Model results for parasite reproduction comparing the antibiotic + parasite treatment relative to the parasite treatment (intercept). Coefficients of the zero-inflation model show the probability of obtaining a zero value.

\begin{tabular}{|l|l|l|l|l|}
\hline Zero Inflation Model & Coefficient & Standard error & Z value & P value \\
\hline Intercept & 3.841 & 1.180 & 3.255 & $0.001 *$ \\
\hline Antibiotic + parasite & 1.765 & 2.267 & 0.778 & 0.436 \\
\hline Week & -0.867 & 0.218 & -3.982 & $<0.001 *$ \\
\hline Antibiotic + parasite: Week & -0.519 & 0.471 & -1.102 & 0.270 \\
\hline & & & & \\
\hline Conditional Model & & & & \\
\hline Intercept & 4.362 & 0.334 & 13.069 & $<0.001 *$ \\
\hline Antibiotic + parasite & -1.285 & 0.417 & -3.083 & $0.002 *$ \\
\hline Week & 0.021 & 0.047 & 0.441 & 0.660 \\
\hline Antibiotic + parasite: Week & 0.177 & 0.058 & 3.058 & $0.002 *$ \\
\hline
\end{tabular}


Table 3. Model results for host reproduction comparing the antibiotic treatment relative to the control treatment (intercept). Coefficients of the zero-inflation model show the probability of obtaining a zero value.

\begin{tabular}{|l|l|l|l|l|}
\hline Zero Inflation Model & Coefficient & Standard Error & Z Value & P Value \\
\hline Intercept & -0.812 & 0.540 & -1.503 & 0.132 \\
\hline Antibiotic & -2.166 & 0.700 & -2.813 & $0.005^{*}$ \\
\hline Week & -0.121 & 0.0587 & -2.062 & $0.039^{*}$ \\
\hline & & & & \\
\hline Conditional Model & & & & \\
\hline Intercept & 1.107 & 0.095 & 11.676 & $<0.001 *$ \\
\hline Antibiotic & 0.190 & 0.105 & 1.813 & 0.070 \\
\hline Week & 0.030 & 0.010 & 2.890 & $0.004 *$ \\
\hline
\end{tabular}

Table 4. Model results for host reproduction comparing the antibiotic + parasite treatment relative to the parasite treatment (intercept). Coefficients of the zero-inflation model show the probability of obtaining a zero value.

\begin{tabular}{|l|l|l|l|l|}
\hline Zero Inflation Model & Coefficient & Standard Error & Z Value & P Value \\
\hline Intercept & -7.756 & 1.688 & -4.596 & $<0.001^{*}$ \\
\hline Antibiotic + parasite & 4.667 & 1.702 & 2.742 & $0.006^{*}$ \\
\hline Week & 2.609 & 0.523 & 4.989 & $<0.001^{*}$ \\
\hline Antibiotic + parasite: & -1.820 & 0.505 & -3.603 & $<0.001^{*}$ \\
\hline Week & & & & \\
\hline Conditional Model & & & & \\
\hline Intercept & 1.705 & 0.220 & 7.733 & $<0.001 *$ \\
\hline
\end{tabular}


bioRxiv preprint doi: https://doi.org/10.1101/2020.11.07.372813; this version posted November 8, 2020. The copyright holder for this preprint (which was not certified by peer review) is the author/funder, who has granted bioRxiv a license to display the preprint in perpetuity. It is made available under aCC-BY-NC 4.0 International license.

\begin{tabular}{|l|l|l|l|l|}
\hline Antibiotic + parasite & 0.337 & 0.252 & 1.338 & 0.181 \\
\hline Week & -0.201 & 0.111 & -1.812 & 0.070 \\
\hline Antibiotic + parasite: & -0.061 & 0.121 & -0.502 & 0.616 \\
Week & & & & \\
\hline
\end{tabular}

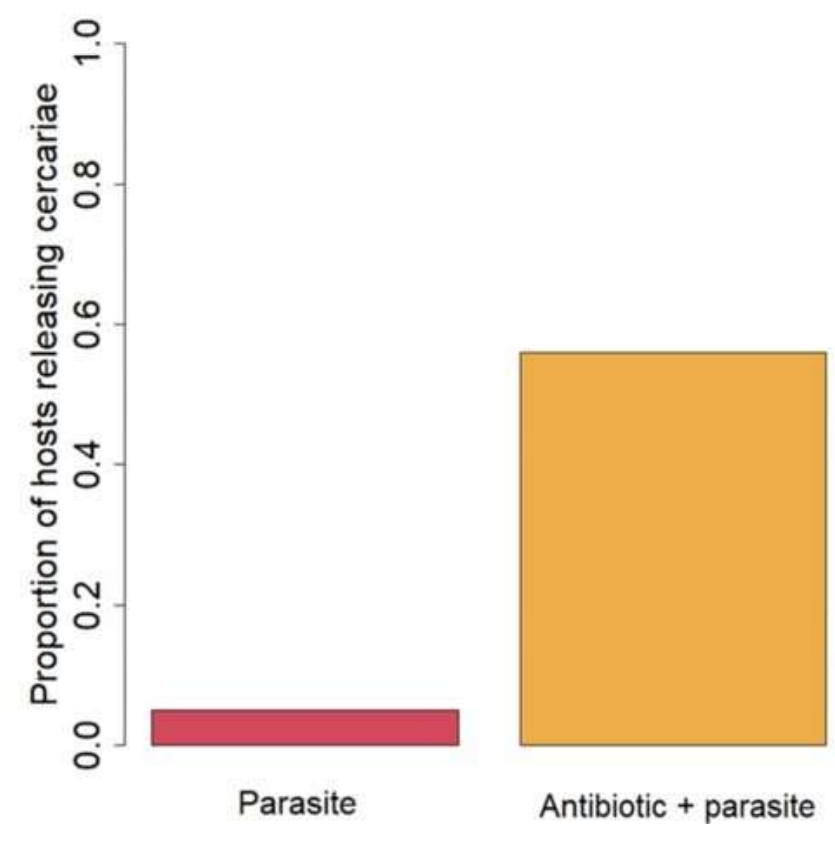

Figure 1. Proportion of exposed Schistosoma mansoni infected snails that released cercariae on week 4. 


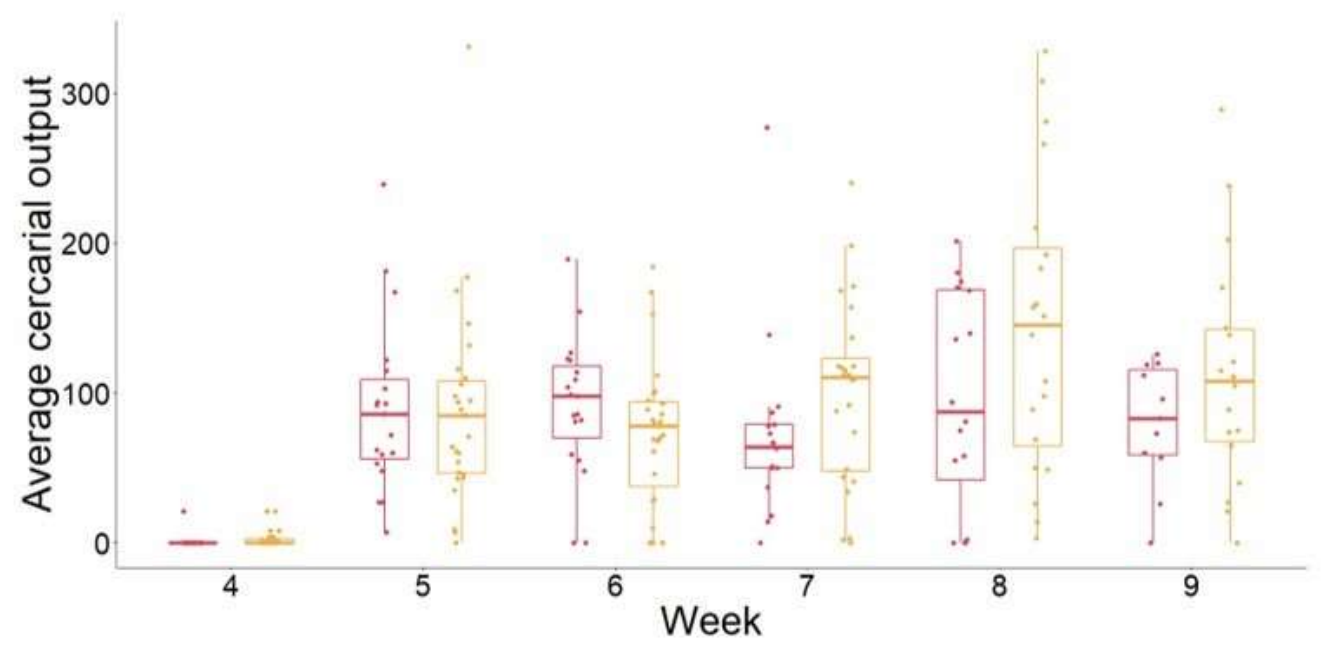

Figure 2. Boxplots of average cercarial output showing increased output as the infection progresses in the antibiotic + parasite compared to the parasite only treatments. Antibiotic + parasite treatment is shown in gold, and parasite only treatment in red. Overlaid data points are jittered for visualization. 
(A)

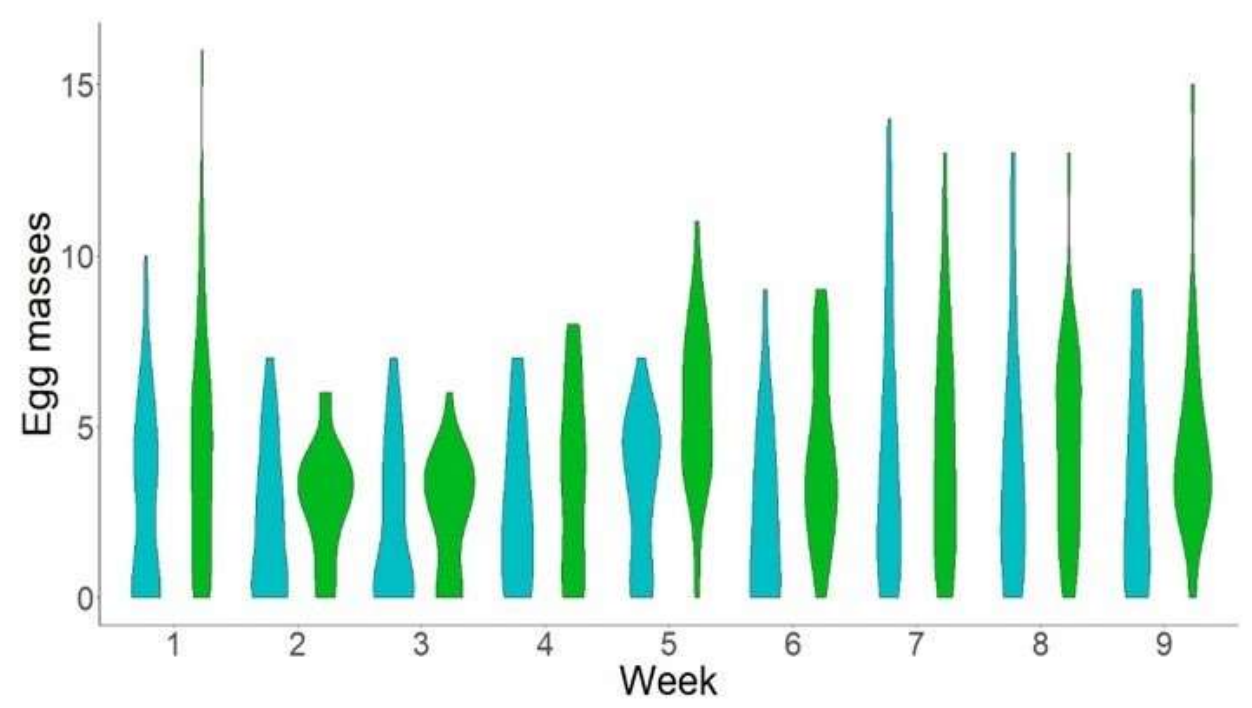

(B)

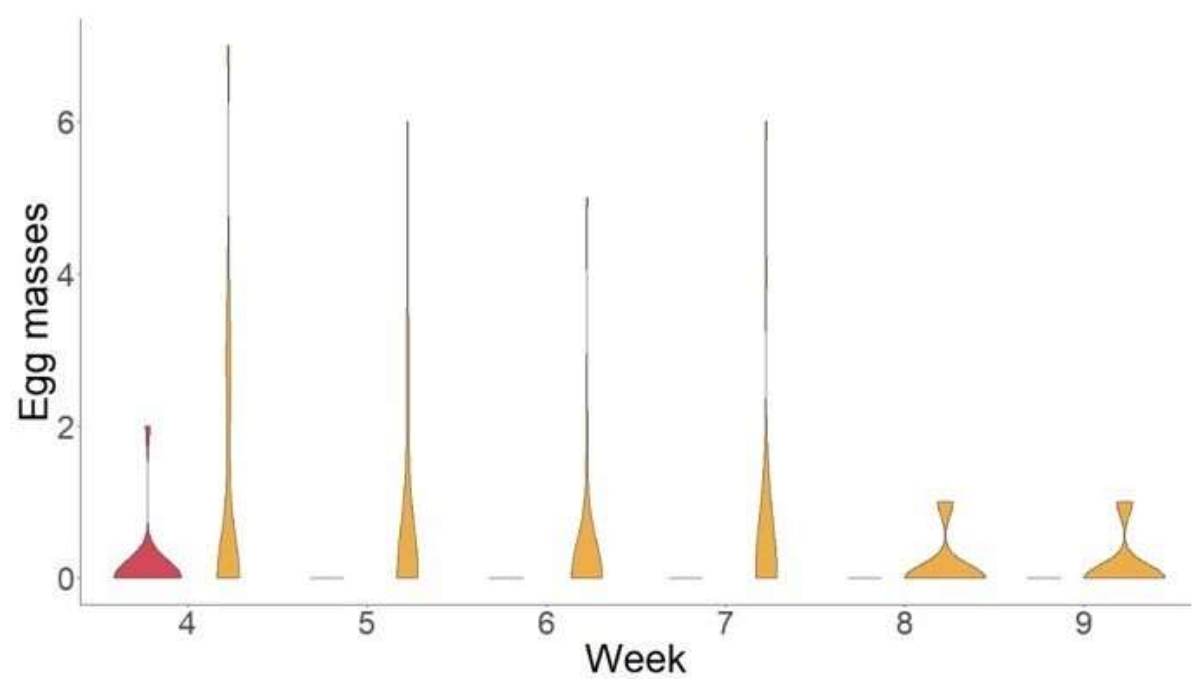

Figure 3. (A) Host reproductive output showing an increased likelihood of laying eggs for the antibiotic treatment (green) compared to the control treatment (blue) (B) Post-castration period showing a higher probability of laying eggs and delayed castration period of the antibiotic + parasite (gold) treatment compared to parasite (red) treatment during weeks 4-9 . 
bioRxiv preprint doi: https://doi.org/10.1101/2020.11.07.372813; this version posted November 8, 2020. The copyright holder for this preprint (which was not certified by peer review) is the author/funder, who has granted bioRxiv a license to display the preprint in perpetuity. It is made available under aCC-BY-NC 4.0 International license.
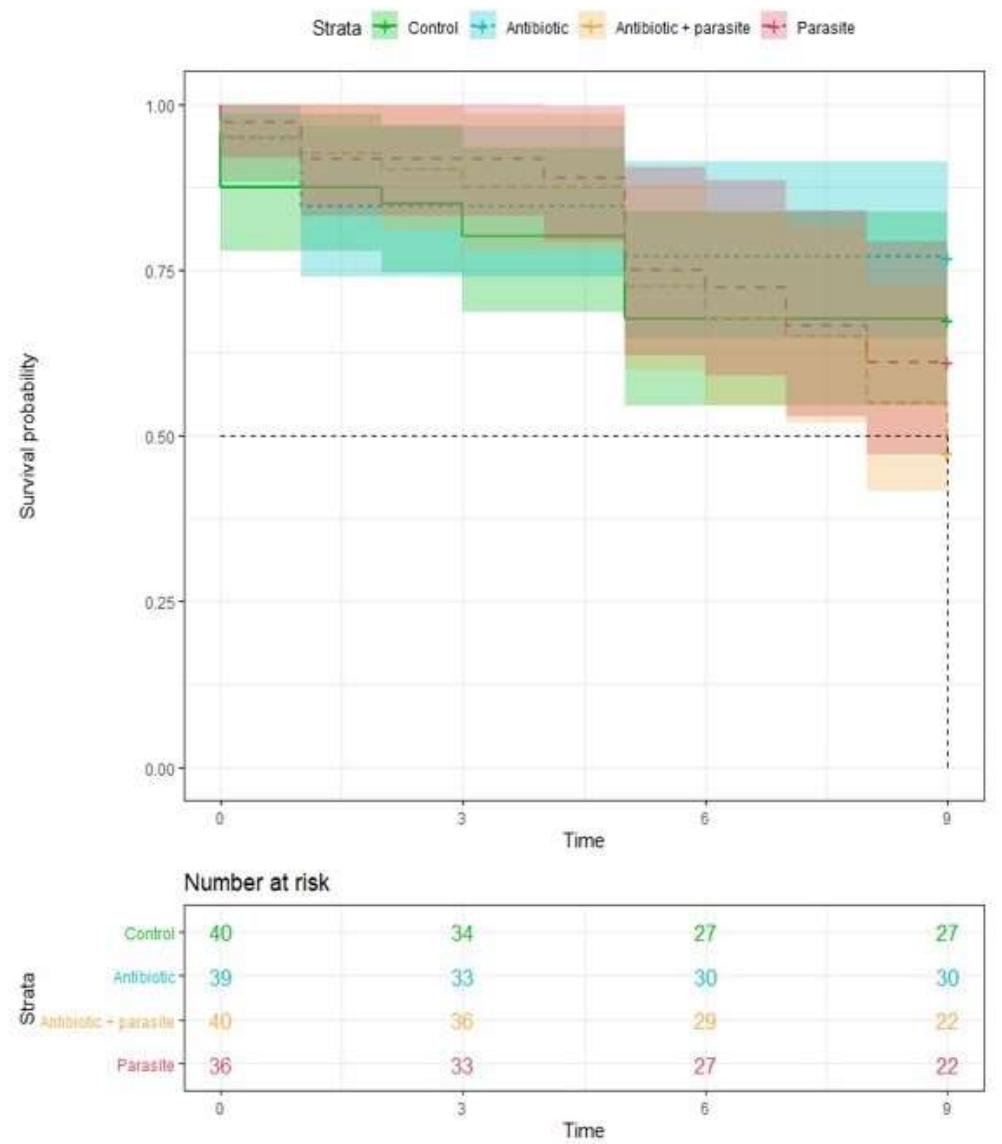

Figure 4. Survival probability of treatment snails during the 9-week experiment. 

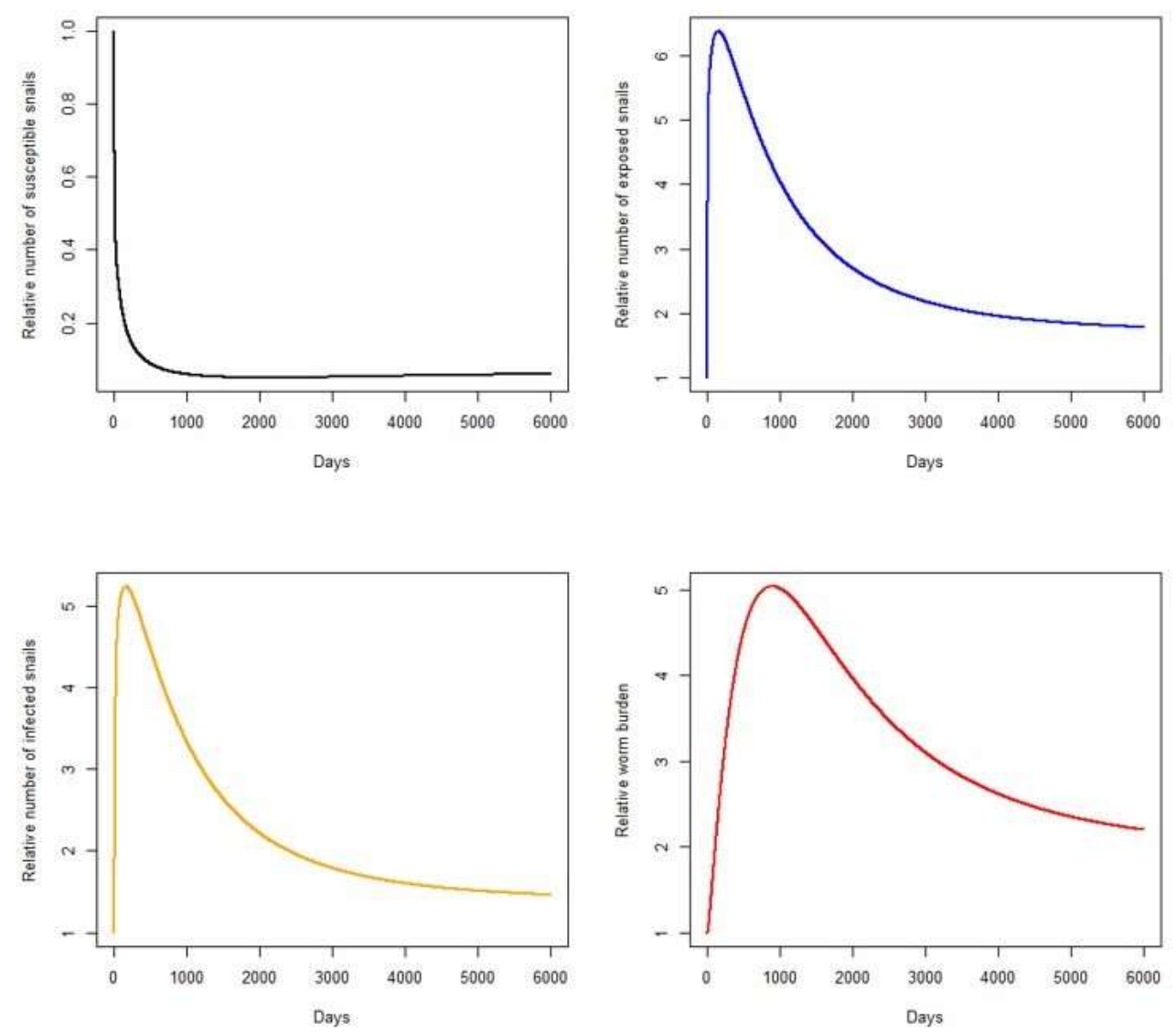

Figure 5. Model output showing the relative number of susceptible snails, exposed snails, infected snails, and mean worm burden in the human population in the antibiotic versus control scenario $(\mathrm{y}$ values $=$ antibiotic scenario values / control scenario values). Y axis values greater than 1 suggest the antibiotic scenario has larger amounts of the state variable. Y axis values less than 1 suggest the antibiotic scenario has smaller amounts of the state variable. 


\section{Mathematical model}

In order to further understand how antibiotic contamination may alter disease dynamics, we adapted the differential equation model of Hoover et al. (2020). We used a base model without predation or agrochemical pollution, including snail reproduction associated with fecundity compensation (Minchella et al., 1981) and delayed castration, and assumed all female S. mansoni worms are paired. These alterations result in the set of differential equations and dynamic variables below. Here, S, E, and I represent susceptible, exposed, and infected snails, respectively. W represents the mean worm burden in the human population with $\mathrm{M}$ representing the number of female worms, $\mathrm{C}$ representing infective parasite cercariae, and $\mathrm{N}$ the total snail population:

$$
\begin{gathered}
\frac{d S}{d t}=f_{N}\left(1-\frac{N}{\varphi_{N}}\right)(S+\chi E+\rho I)-\mu_{N} S-\beta M S \\
\frac{d E}{d t}=\beta M S-\mu_{N} E-\sigma E \\
\frac{d I}{d t}=\sigma E-\left(\mu_{N}+\mu_{I}\right) I \\
\frac{d W}{d t}=\lambda C-\left(\mu_{H}+\mu_{W}\right) W \\
M=0.5 W H m v \pi_{m} \\
C=\theta I \pi_{C} \\
N=S+E+I
\end{gathered}
$$

We used our data to calculate the percent change in snail and parasite life history characteristics in response to antibiotic exposure and altered model parameters accordingly (Table S1). This exercise is intended only to make qualitative predictions on how antibiotic 
exposure may alter disease dynamics. Analysis was run using the deSolve package in R.3.6.3

(Soetaert et al., 2010).

Table S1. Model parameters and estimates from Hoover et al. 2020 and antibiotic altered parameters.

\begin{tabular}{|c|c|c|c|}
\hline Variable & Description & Ref Estimate & $\begin{array}{c}\text { Antibiotic } \\
\text { altered } \\
\text { estimate }\end{array}$ \\
\hline$f_{N}$ & Per-capita snail reproduction & ${ }^{\mathrm{h}} 0.60$ & 0.81 \\
\hline$\varphi_{N}$ & $\begin{array}{l}\text { Density-dependent snail population } \\
\text { growth parameter }\end{array}$ & ${ }^{\mathrm{h}} 10^{4}$ & \\
\hline$\chi$ & $\begin{array}{l}\text { Reproduction of E relative to } \mathrm{S} \\
\text { (due to fecundity compensation) }\end{array}$ & 1.332; This study & 1.174 \\
\hline$\rho$ & $\begin{array}{l}\text { Reproduction of I relative to } \mathrm{S} \\
\text { from incomplete castration }\end{array}$ & 0.007; This study & 0.115 \\
\hline$\mu_{N}$ & Natural snail mortality rate & ${ }^{\mathrm{h}} 0.017$ & 0.015 \\
\hline $\boldsymbol{\beta}$ & $\begin{array}{l}\text { Human to snail infection } \\
\text { probability }\end{array}$ & e $6.67 \times 10^{-7}$ & $8.66 . \times 10^{-7}$ \\
\hline$\sigma$ & $\begin{array}{c}\text { Conversion rate from exposed to } \\
\text { infected }\end{array}$ & ${ }^{\mathrm{a}} 0.025$ & \\
\hline$\mu_{I}$ & $\begin{array}{l}\text { Additional mortality rate of } \\
\text { infected snails }\end{array}$ & ${ }^{\mathrm{a}} 0.083$ & 0.107 \\
\hline$\lambda$ & $\begin{array}{l}\text { Snail to human infection } \\
\text { probability }\end{array}$ & $\mathrm{d} 7.5 \times 10^{-8}$ & \\
\hline$\mu_{H}$ & $\begin{array}{l}\text { Mortality rate of adult worms } \\
\text { associated with human mortality }\end{array}$ & e $4.57 \times 10^{-5}$ & \\
\hline$\mu_{W}$ & Mortality rate of adult worms & b $8.3 \times 10^{-4}$ & \\
\hline$m$ & Eggs produced per day & $\mathrm{d} 432$ & \\
\hline$v$ & Miracidial viability & ${ }^{\mathrm{c}} 0.084$ & \\
\hline$\pi_{m}$ & Miracidia-hours & ${ }^{\mathrm{f}} 6.22$ & \\
\hline $\boldsymbol{\theta}$ & Relative cercarial shedding rate & d 15.6 & 22.2 \\
\hline$\pi_{C}$ & Cercariae-hours & $\mathrm{g}_{14.22}$ & \\
\hline
\end{tabular}


${ }^{\mathrm{a}}$ Anderson and May 1991, ${ }^{\mathrm{b}}$ Goddard and Jordan 1980, ${ }^{\mathrm{c}}$ Halstead et al. 2018, ${ }^{\mathrm{d}}$ Hoover et al.

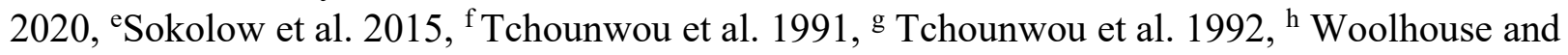
Chandiwana 1990

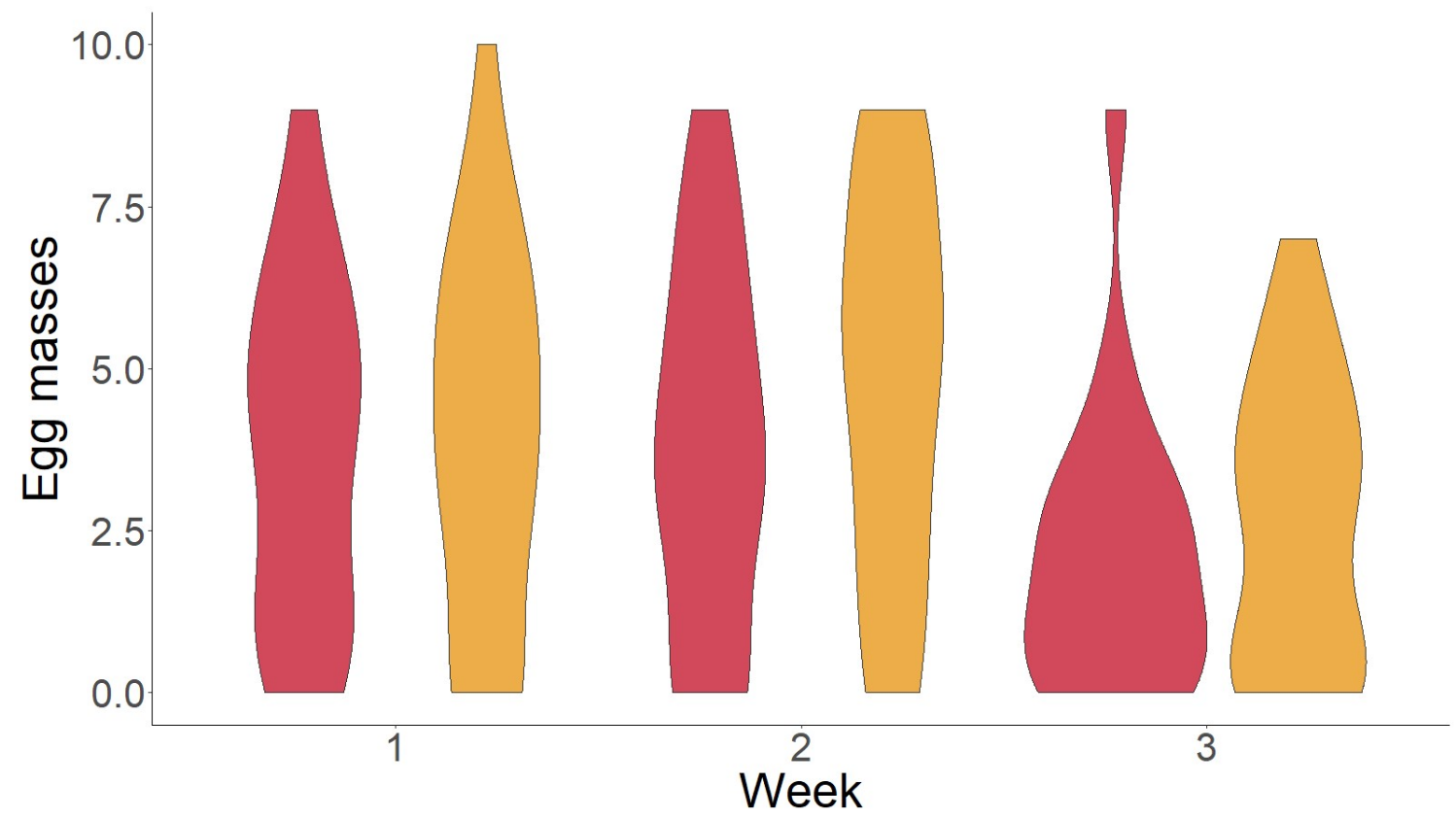

Figure S1. Pre-castration periods showing an initially similar reproductive output in the antibiotic + parasite treatment (gold) when compared to the parasite treatment (red) during weeks 1-3. 


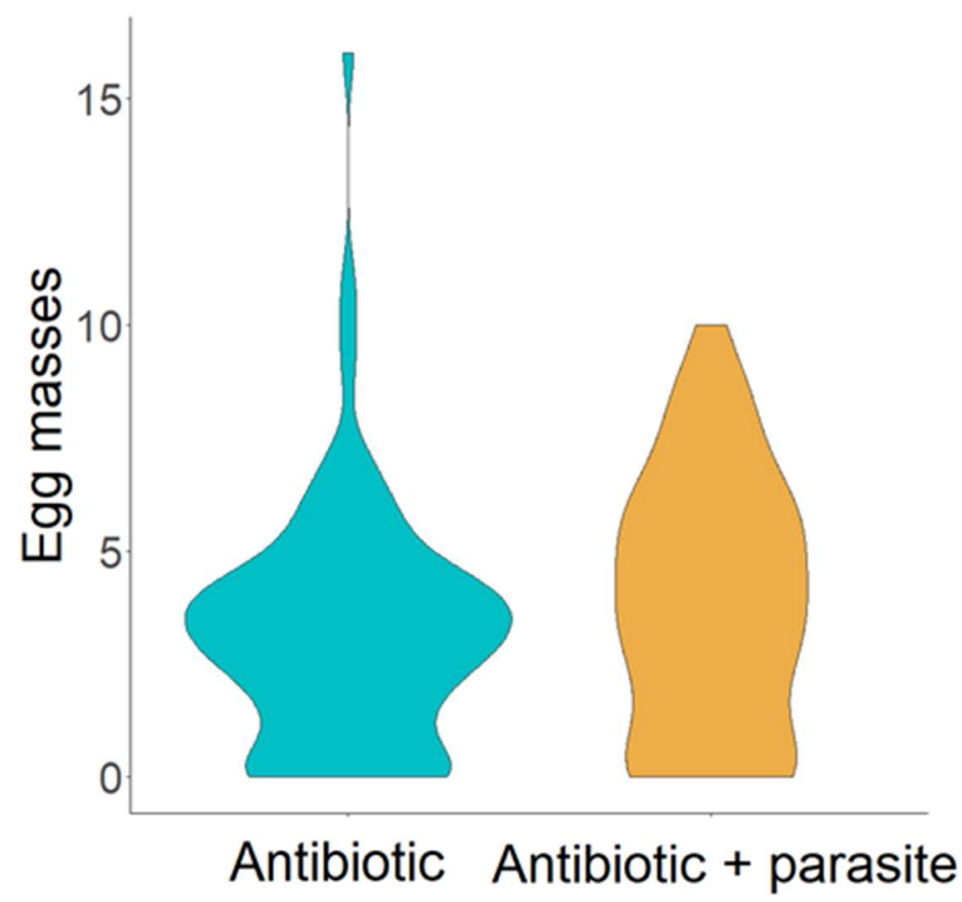

Figure S2: Host reproductive output by antibiotic + parasite treatment is significantly larger than antibiotic only treatment during the first 3 weeks of infection. Mean values over this period were used to inform the model.

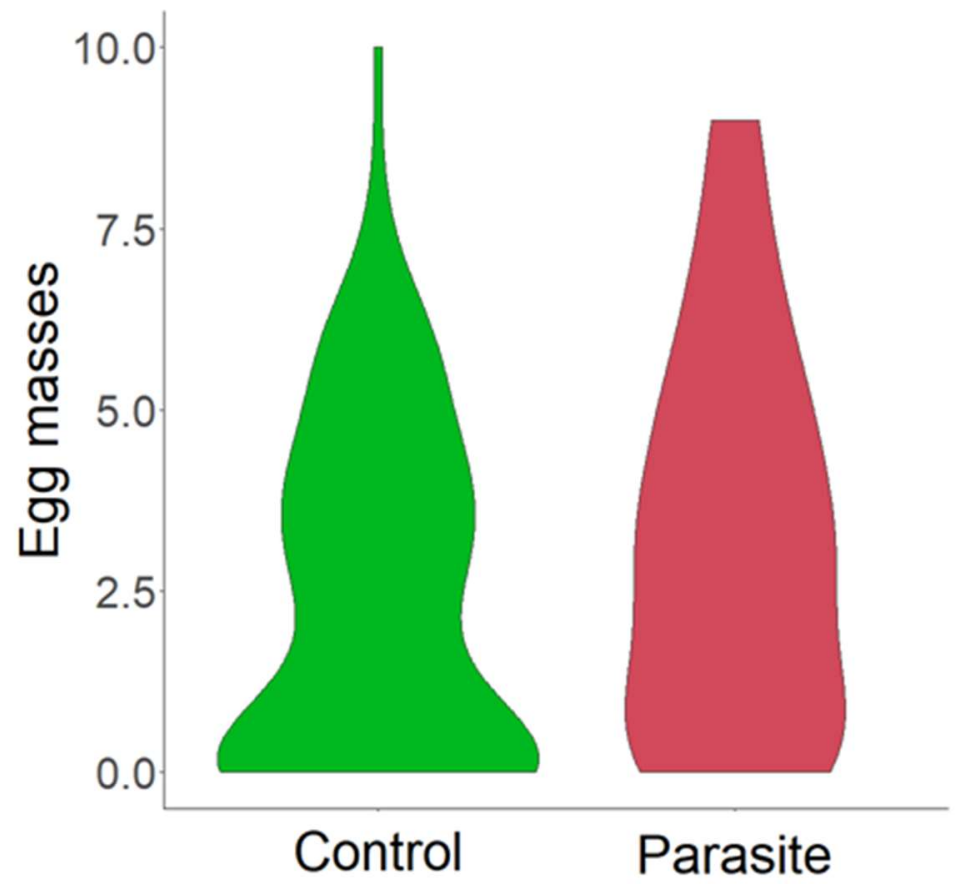

Figure S3: Host reproductive output of the control treatment compared to the parasite treatments prior to castration. Mean values over this period were used to inform the model. 